DOI: $10.20287 /$ doc.d20.lt1

\title{
O filme-ensaio: da teoria à análise
}

\author{
Juliano José de Araújo*
}

Teixeira, F. E. (Org.). (2015). O ensaio no cinema: formação de um quarto domínio das imagens na cultura audiovisual contemporânea. São Paulo: Hucitec. ISBN 978-85-8404-048-3

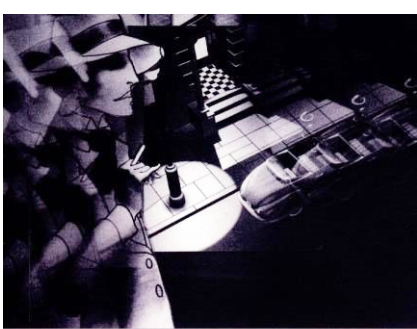

OENSAIO NO CINEMA formaç̃̃o de um Quarto domínio DAS IMAGENS NA CUITURA AUDIOVISUAL CONTEMPORÂNEA francisco Elinaldo teixeira ORGANizą̧ÄO

HUCITEC EDITORA

Recém publicado pela Editora Hucitec, o livro $O$ ensaio no cinema: formação de um quarto domínio das imagens na cultura audiovisual contemporânea, organizado por Francisco Elinaldo Teixeira, constitui-se em uma contribuição ímpar para a teoria e análise do ensaio no cinema. Teixeira, que é professor do Programa de Pós-Graduação em Multimeios da UNICAMP, tem, desde o início dos anos 2000, publicado os resultados de suas pesquisas em obras em que, como ele mesmo afirma, "a questão da relação entre cinema e pensamento é constantemente posta em foco". Assim, este último livro apresenta, de certa forma, "uma consciência mais aguda" do autor sobre "aspectos de envergadura a respeito do cine-ensaio". O resultado não poderia ter sido melhor: trata-se da primeira antologia, no Brasil, que, como nos informa Teixeira, reúne um conjunto significativo de reflexões de autores brasileiros e estrangeiros tendo como tema o ensaio no cinema.

* Universidade Federal de Rondônia - UNIR, Campus de Vilhena, Departamento de Comunicação Social/Jornalismo. 76980-000, Vilhena-RO, Brasil. E-mail: araujojuliano@gmail.com 
A obra é dividida em duas partes. A primeira, denominada "Polindo um conceito: cartografias do ensaio no cinema", traz sete textos que procuram circunscrever a definição de ensaio no cinema, suas origens, correspondências e transposições da filosofia e literatura, como também sua presença no cinema, desde o período clássico à contemporaneidade etc. Carlos Ebert, com larga experiência como diretor de fotografia, é o autor do capítulo "Diga-me de onde olhas e te direi se reconhecerás o que está à tua frente" que abre a coletânea. Nesse texto, Ebert empreende uma discussão sobre o ponto de vista no cinema, examinando-o à luz de vários exemplos fílmicos, como dos cineastas Alfred Hitchcock e Jean-Luc Godard. Destaca-se, em sua argumentação, a figura do ponto de vista subjetivo. $\mathrm{O}$ autor, em uma perspectiva histórica, problematiza o papel de sua mobilidade, uma vez que passou a ter uma função cada vez mais importante na narrativa audiovisual, acentuada pela miniaturização das câmeras de hoje.

O texto seguinte, "Um conceito fugidio: notas sobre o filme-ensaio", de Antonio Weinrichter López (UC3M), apresenta um mapeamento do conceito de filme-ensaio. Para tanto, Weinrichter aborda a presença do filme-ensaio na programação e publicações de festivais de cinema e museus, instituições que acabam, em certa medida, legitimando sua existência recente, notadamente a partir do final dos anos 1990. O autor investiga também a bibliografia dedicada à noção de ensaísmo cinematográfico, realizando um panorama contundente dessas obras, para além do texto de Hans Richter que, junto com o de André Bazin e de Alexander Astruc, são sempre referenciados. Weinrichter destaca a publicação da primeira antologia dedicada ao tema em 1992, em alemão, seguida nos anos seguintes das contribuições anglo-saxãs, em 1995, e da francesa, somente em 2004, dentre outros trabalhos importantes. A partir desse levantamento, o capítulo faz, nas palavras do autor, "uma pequena crônica de alguns dos marcos que permitiram postular" a existência do ensaio "como manifestação histórica".

Henri Arraes Gervaiseau (USP), no texto "Escrituras e figurações do ensaio", propõe a revisão bibliográfica de textos clássicos dedicados ao ensaio, como a tradição que foi inaugurada pelo francês Michel de Montaigne, passando pelos alemães Theodor Adorno e Max Bense. Tendo em vista que se trata de um campo novo, ainda em fase de configuração, Gervaiseau destaca a necessidade e a importância do diálogo com outras áreas do conhecimento, por exemplo, a teoria e a crítica literária. Desses autores, Gervaiseau ressalta o aspecto do ensaio como engajamento de uma experiência e uma escrita que se faz em processo, cujas formas e composição do discurso privilegiam a função poética da linguagem com "a ambiguidade, o jogo de palavras e a polissemia". 
O capítulo é concluído com a análise de algumas das características do ensaio audiovisual, enfatizando-se a diversidade de matérias de expressão acionadas, a relação com a memória e a montagem, a partir de filmes de Alain Resnais, Chris Marker, Eduardo Coutinho, Harun Farocki e Jean-Luc Godard.

"Do filme-ensaio ao mockumentary", de autoria de Robert Stam (NYU), examina a hibridização entre o documentário e a ficção na constituição do que ele denomina de "um recurso estético radical". Stam problematiza esse processo a partir de vários exemplos, notadamente dos cinemas novos, os quais trouxeram elementos documentais aos filmes de ficção, e do antropólogo-cineasta Jean Rouch, que, segundo o autor, introduziu elementos ficcionais nos documentários, no caso, em seus filmes de psicodrama. A argumentação do texto de Robert Stam prossegue com a conceituação do filme-ensaio, discutida, em particular, a partir do livro The essay-film: from Montaigne, after Marker, de Timothy Corrigan, e com farta análise e comentário de obras fundamentais do gênero. $\mathrm{O}$ autor finaliza seu texto com o estudo de alguns falsos documentários, destacando que as "ficções flexionadas documentariamente" e os "documentários ficcionalizados" configuram-se em "uma importante fonte de criatividade politicamente consciente".

O próximo texto, denominado "A falsa ficção", cujo autor é o cineasta Joel Pizzini, investiga uma categoria de filmes que, apesar de se darem a ver como "espetáculos encenados", com a valorização da performance/fabulação das personagens, cotejam o campo do documentário. Fundamentado no pensamento do filósofo Gilles Deleuze, notadamente a ideia de "potência do falso", Pizzini caracteriza esse tipo de filme que, segundo ele, é derivado do filmeensaio. Iracema, uma transa amazônica (1976), de Jorge Bodansky e Orlando Senna; Documentário (1966), de Rogério Sganzerla; e Câncer (1972), de Glauber Rocha, são alguns dos filmes brasileiros destacados pelo autor e que são representativos dessa categoria. Joel Pizzini conclui afirmando que a "falsa ficção" constitui-se no aspecto mais instigante do cinema brasileiro contemporâneo, manifestada em filmes como Serras da desordem (2006), de Andrea Tonacci; O céu sobre os ombros (2010), de Sérgio Borges; e Branco sai, preto fica (2014), de Adirley Queiroz.

Rodrigo Gontijo (UNICAMP), em "Filmes em atos performáticos: do cinema expandido ao live cinema", oferece uma contextualização histórica do live cinema, prática que, como nos informa o autor, tem mais de dez anos de existência. Gontijo remete-nos aos anos 1960, quando a expressão cinema expandido começou a ser empregada por alguns realizadores, como Jonas Mekas, para definir uma prática cinematográfica que dialoga com outras manifestações artísticas (dança, fotografia, música, performance), além de romper com a sala 
escura, abarcando novos espaços. A partir daí, o cinema expandido não parou de ser reinventado nas décadas seguintes. Esse processo foi intensificado com o vídeo e a posterior digitalização, sendo discutido pelo autor em seus momentos mais representativos, até que o termo live cinema, já usado no início do século XX para definir o acompanhamento musical ao vivo durante as projeções dos filmes silenciosos, foi retomado para definir esse tipo de prática em que "atos performáticos são apresentados enunciados mais rítmicos, metalinguísticos, subjetivos e ensaísticos”.

O próximo texto, intitulado "Para além dos domínios da ficção, do documentário e do experimental, o ensaio como formação de um quarto domínio do cinema?", de autoria do organizador da obra, Francisco Elinaldo Teixeira (UNICAMP), procura discutir a pertinência de se considerar o ensaio como um quarto domínio do cinema. Para além dos três domínios do período clássico o ficcional, o documentário e o experimental -, Teixeira argumenta que o advento do cinema moderno no período pós-guerra (o Neorrealismo, a Nouvelle Vague, o Cinema Novo Brasileiro e o Cinema Novo Alemão) abalou profundamente os modelos tradicionais, possibilitando que o conceito de ensaio surgisse. Nesse contexto, o autor procura discutir as especificidades desse novo domínio em um percurso denso, o qual procura compreender suas primeiras manifestações na história do cinema e sua presença constante dos anos 1990 para cá, momento também em que as reflexões sobre o filme-ensaio começam a ser mais substanciais.

A segunda parte, intitulada "Balizando um conceito: o filme-ensaio e a diversidade de suas práticas", apresenta seis capítulos dedicados à análise de diferentes experiências de filme-ensaio. O primeiro, "O filme-ensaio e a voz política na Grã-Bretanha", de Gilberto Alexandre Sobrinho (UNICAMP) e Cecília Mello (USP), analisa um conjunto de realizações fílmicas britânicas das décadas de 1970 e 1980 dos artistas Laura Mulvey e Peter Wollen, Derek Jarman e Isaac Julien. Trabalhando em parceria, Mulvey e Wollen fizeram documentários e filmes-ensaios de abordagem feminista, dos quais se destaca Riddles of the Sphinx, de 1977, que é estudado pelos autores, tendo em vista o fato de repercutir as ideias e conceitos presentes no artigo "Prazer visual e cinema narrativo", de Mulvey. Já Derek Jarman realizou doze longas com diferentes nuances ensaísticas, tais como a subjetividade, o intimismo, o emprego de texturas, filtros etc., além de ter a homossexualidade como sua temática mais cara. Sobrinho e Mello sugerem no texto que o uso do formato Super8 foi fundamental para o desenvolvimento do ensaísmo de Jarman. Por fim, Isaac Julien fez um conjunto de filmes com um forte investimento poético na fronteira entre ficção e documentário aliada a temas relacionados aos negros, 
dos quais são analisados as biografias fílmicas Looking for Langston, que homenageou o poeta negro norte-americano Langston Hughes, e Frantz Fanon back skin white mask, dedicada ao médico, ativista e intelectual Frantz Fanon. Destaca-se, nesse conjunto de filmes, como argumentam os autores, "o questionamento dos temas relacionados às mulheres, aos gays e aos negros na esfera artística".

O capítulo seguinte, "A teatralidade como vetor do ensaio fílmico no documentário brasileiro contemporâneo", de autoria de Ismail Xavier (USP), apresenta uma análise de Jogo de cena, filme de Eduardo Coutinho que problematiza a questão da representação e, literalmente, embaralha os tênues limites entre ficção e realidade, mise-en-scène e automise-en-scène. Xavier evoca o conceito de filme-ensaio, formulado por Hans Richter, na década de 1940, e também o de Theodor Adorno, pontuando que as obras de cineastas do cinema moderno como Resnais, Marker, Godard, Straub e Kluge constituem-se em importantes referenciais. Também é acionado em sua análise o conceito de teatralidade proposto por Josette Féral. Tendo em vista as perspectivas abertas pelo ensaio, o autor argumenta que nada melhor do que estudar, caso a caso, "as marcas formais" desse domínio. Assim, chama a atenção em seu estudo para o filme Jogo de cena e a dimensão reflexiva do ensaio a partir das relações entre cinema, performance e teatro.

Sarah Yakhni, cientista social e documentarista, no texto "Ensaios de Varda: narrativas do desejo", dedica-se à reflexão do filme-ensaio a partir da rica produção fílmica da cineasta Agnès Varda que, há mais de meio século, tem se destacado a realizar "um cinema que pensa o mundo". Procedimentos estilísticos e estratégias de abordagem empregados por Varda, como o acaso, a colagem, a fragmentação e a autorreflexividade são analisados em uma perspectiva qualitativa em alguns de seus filmes, como La pointe courte (1954), L'opéra-mouffe (1958), Salut les cubains (1963), Ulysse (1982) e Les glaneurs et la glaneuse (2000). Para tanto, Yakhni, no decorrer de suas análises, tem a preocupação de situar a produção de Varda no contexto da Nouvelle Vague e suas mudanças de paradigmas cinematográficos, do cinema direto ou verdade e as possibilidades abertas pelos equipamentos mais leves e sincrônicos etc. A autora conclui seu artigo defendendo a ideia de que os filmes de Varda constituem-se como "narrativas do desejo", uma vez que a realizadora deslocase do "ponto de vista de um fora para um dentro".

O próximo capítulo, intitulado "Jean Rouch e o nascimento de um certo filme-ensaio", de autoria de Marcius Freire (UNICAMP), parte da constatação de que a produção audiovisual de não-ficção contemporânea tem sido marcada por um número significativo de filmes que trazem para o primeiro plano "as 
lutas pessoais, os dramas individuais, os conflitos existências" etc. de seus realizadores. Passaporte húngaro (2002), de Sandra Kogut, e 33 (2004), de Kiko Goifman, são, segundo o autor, dois bons exemplos desse tipo de produção que revela traços do que tem sido comumente denominado por alguns estudiosos de filme-ensaio. Nesse sentido, Freire, analisando alguns filmes de Jean Rouch, como Jaguar (1954-67), Moi, un Noir (1958-59), La pyramide humaine (1959-60) e Chronique d'un Été (1960), co-dirigido por Edgar Morin, argumenta que o filme de dispositivo e o filme autobiográfico, considerados como duas ramificações do filme-ensaio, têm justamente suas origens nas estratégias fílmicas empregadas pioneiramente pelo antropólogo-cineasta há mais de meio século.

Em "Por uma câmera contra o status quo: o cine-ensaísmo de Želimir Žilnik", Alfredo Suppia (UNICAMP) desenvolve a hipótese de que o cineasta sérvio tem o ensaio como um elemento fundamental de seu processo criativo, seja em seus filmes de ficção ou documentários. Para tanto, inicialmente, Suppia faz uma incursão na definição de filme-ensaio e apresenta, em seguida, o contexto que deu origem ao movimento cinematográfico conhecido como Onda Negra, que surgiu na Iugoslávia na segunda metade dos anos 1960 e teve como características "a experimentação com a linguagem cinematográfica a serviço de uma postura política de crítica ao regime e às contradições da sociedade de seu tempo". Por fim, a terceira parte do artigo é dedicada ao estudo da obra de Žilnik e de seus elementos estético-narrativos que, como conclui Suppia, acomoda-se "mais confortavelmente no campo do ensaísmo audiovisual".

Candida Maria Monteiro (PUC/RJ), no texto que encerra a segunda parte do livro, intitulado "Di Tella: paixão pelo ensaio", dedica-se à compreensão da obra ensaística do realizador argentino Andrés Di Tella, que é pouco conhecido no Brasil. Tendo como perspectiva teórica o conceito de "documentário do eu" - uma espécie de releitura do documentário autobiográfico -, o qual é marcado pelo "desejo de interferir e recontar fatos históricos", Monteiro analisa dois filmes de Di Tella: La televisión y yo (2001) e Fotografías (2007). Tratase de obras que, segundo a autora, constituem uma espécie de díptico, uma vez que revelam um processo de complementaridade, originando-se uma da outra. Dentre as características do "documentário do eu" de Di Tella, destacase, segundo Monteiro, notadamente a ressignificação de imagens e sons na (re)montagem, à medida em que o realizador trabalha com filmes domésticos, fotos de família, materiais de arquivo de fontes oficiais etc., com o intuito de problematizar a história oficial.

Por fim, a obra é encerrada com um capítulo do organizador, Francisco Elinaldo Teixeira (UNICAMP), denominado "Ao modo de conclusão/abertura 
para um novo capítulo: incidências e avatares de um cine-ensaio no Brasil". Com muita perspicácia, Teixeira realiza neste texto, como ele afirma, "uma espécie de balanço do "estado da arte" do ensaio no cinema. Inicialmente, sintetiza suas principais características, destacando que se constitui em "um objeto: proteico, multiforme, polimorfo, polifônico e polissêmico", além de realizar "passagens entre o documentário e o experimental, como também com a ficção", mas sem se confundir com esses domínios, uma vez que se apresenta como "reflexão do mundo histórico". O livro complementa-se com uma bibliografia geral sobre o filme-ensaio, uma indicação muito relevante para quem quiser se debruçar sobre o assunto. Nesse contexto, acreditamos que o livro O ensaio no cinema: formação de um quarto domínio das imagens na cultura audiovisual contemporânea estabelece-se como uma importante obra de referência sobre o filme-ensaio, uma vez que consegue, com muita propriedade, aliar as reflexões teóricas à análise, sendo, portanto, obra incontornável sobre o tema. 